\title{
Metabolomics Study of Serum from a Chronic Alcohol-Fed Rat Model Following Administration of Defatted Tenebrio molitor Larva Fermentation Extract
}

\author{
Ra-Yeong Choi ${ }^{1,+}{ }^{+}$, Moongi Ji ${ }^{2,+}$, Mi-Kyung Lee ${ }^{1, *}$ and Man-Jeong Paik ${ }^{2, *}$ \\ 1 Department of Food and Nutrition, Sunchon National University, Suncheon 57922, Korea; \\ fkdud1304@naver.com \\ 2 College of Pharmacy, Sunchon National University, Suncheon 57922, Korea; wlansrl@naver.com \\ * Correspondence: leemk@scnu.ac.kr (M.-K.L.); paik815@scnu.ac.kr (M.-J.P.); Tel.: +82-61-750-3656 (M.-K.L.); \\ +82-61-750-3762 (M.-J.P.) \\ + These authors have contributed equally to this work.
}

Received: 9 September 2020; Accepted: 27 October 2020; Published: 29 October 2020

check for updates

\begin{abstract}
We have previously showed that defatted mealworm fermentation extract (MWF) attenuates alcoholic liver injury by regulating lipid, inflammatory, and antioxidant metabolism in chronic alcohol-fed rats. The current metabolomics study was performed to monitor biochemical events following the administration of MWF (daily for eight weeks) to a rat model of alcoholic liver injury by gas chromatography-tandem mass spectrometry (GC-MS/MS). The levels of 15 amino acids (AAs), 17 organic acids (OAs), and 19 free fatty acids (FFAs) were measured in serum. Analysis of variance (ANOVA), principal component analysis (PCA), and partial least squares discriminant analysis (PLS-DA) were used to compare the levels of 51 metabolites in serum. In particular, 3-hydroxybutyric acid (3-HB), pyroglutamic acid (PG), octadecanoic acid, and docosahexaenoic acid (DHA) were evaluated as high variable importance point (VIP) scores and PCA loading scores as determined by PLS-DA and PCA, and these were significantly higher in the MWF and silymarin groups than in the EtOH group. MWF showed a protective effect from alcohol-induced liver damage by elevating hepatic $\beta$-oxidation activity, and serum 3-HB levels were significantly higher in the MWF group than in the EtOH control group. Glycine levels were higher in the MWF group than in the EtOH group, and PG levels (related to glutathione production) were also elevated, indicating a reduction in alcohol-related oxidative stress. In addition, MWF is protected from alcohol-induced inflammation and steatosis by increasing serum DHA, palmitic, and octadecanoic acid levels as compared with the EtOH group. These results suggest that MWF might attenuate alcoholic liver disease, due to its anti-inflammatory and antioxidant effects by up-regulating hepatic $\beta$-oxidation activity and down-regulating liver FFA uptake.
\end{abstract}

Keywords: edible insect; metabolomics; metabolic profiling analysis; gas chromatography-tandem mass spectrometry

\section{Introduction}

Edible insects offer a promising food source for future generations, due to their rich nutrient contents, sustainability, and low environmental impacts [1]. The yellow mealworm (larva of the Tenebrio molitor) is one of the insects produced on an industrial scale as a food or feedstuff [2]. Many studies have demonstrated that yellow mealworms have multiple beneficial physiological effects, such as anti-obesity [3], anti-osteoporotic [4], antioxidant [5], and anti-hypertensive effects [6]. 
Recently, Cho et al. [7] reported that yellow mealworm alcalase hydrolysates protected AML12 mouse liver cells against reactive oxygen species. Our previous study showed for the first time that defatted mealworm fermentation extract (MWF) might attenuate alcohol-induced liver injury by regulating the lipogenic and inflammatory pathways and the antioxidant defense system and by partially altering gut microbial composition [8].

Alcoholic liver disease (ALD) is a major cause of morbidity and mortality worldwide among individuals that consistently drink large amounts of alcohol [9]. Chronic alcohol intake causes mitochondrial dysfunction, oxidative stress, defective protein metabolism, and alcoholic fatty liver, which can progress to steatohepatitis, cirrhosis, and hepatocellular carcinoma [10]. Malnutrition of proteins exacerbates abnormal amino acid metabolism, which is known to occur in alcohol-consuming patients, with reduced circulating branched amino acids (BCAAs) [11,12]. In a recent study, it was reported that not only BCAAs supply improves liver disease, but also essential amino acid supply that reduces liver damage in rats chronically administered ethanol [13]. Free fatty acids (FFAs) can damage biological membranes, and their accumulation in the liver is partly responsible for the functional and morphological changes characteristic of alcoholic liver disease [14]. Therefore, it is important to monitor amino acids (AAs), organic acids (OAs), and FFAs metabolism in ALD.

Metabolomics provides a means of characterizing metabolic phenotypes and is used to identify metabolic disorders and discover biomarkers that can be used to diagnose or monitor diseases [15]. Ma et al. [16] recently reported that 35 metabolites were significantly altered in the liver of alcohol diet compared to the isocaloric control diet mice. Dong et al. [17] also demonstrated that chronic alcohol consumption induced significant alteration of serum FAs and bile acids by metabolic pathway analysis. The previous metabolomics study reported threonine, guanidinosuccinate, and glutamine as biomarkers in plasma of humans with alcohol-induced liver injury [18]. In addition, Lian et al., also reported oleamide and myristamide as biomarkers in the serum of patients with alcoholic cirrhosis [19]. However, no systematic metabolic study has been performed in ALD. Star pattern recognition analysis is a useful tool for distinguishing metabolic abnormalities [20,21], and principal component analysis (PCA), and partial least squares-difference analysis (PLS-DA), and multivariate analysis are useful for interpreting metabolomic data sets [22]. Therefore, in this study, target metabolome studies on serum AAs, OAs, and FFAs were performed by profiling, star pattern recognition, and multivariate analyses to assess hepatoprotective effects of MWF against the development of alcoholic steatosis in the ALD rat model. We have integrated the results of this metabolic profiling and previous molecular mechanism analyses [8], providing an improved understanding for the protective effects of MWF on chronic alcohol-induced liver injury.

\section{Results}

\subsection{Metabolic Profiling Analysis and Univariate Analysis}

In serum, 51 metabolites, including 15 AAs, 17 OAs, and 19 FFAs, were determined by GC-MS/MS analysis. In all six study groups, threonine was the most abundant AA at the end of the 8-week study period, and in all groups except the MWF100 group, followed by serine and isoleucine, whereas in the MWF100 group, serine was followed by threonine. In the Con and EtOH groups, lactic acid was the most abundant OA and was followed by pyruvic acid and 3-hydroxybutyric acid (3-HB). Whereas, in the MWF and silymarin groups, lactic acid was most abundant, followed by 3-HB and pyruvic acid. In metabolic profiling analysis, acetoacetic acid (2.15 2.66-fold), 3-HB (6.48 18.53-fold), and oxalic acid (1.82 2.62-fold) showed the greatest change compared to the control group. In all groups, eicosadienoic acid $\left(\mathrm{C}_{20: 2}\right)$ was the most abundant FFA and was followed by arachidonic acid $\left(\mathrm{C}_{20: 4}\right)$, and docosatetraenoic acid $\left(\mathrm{C}_{22: 4}\right)$. Of the 51 metabolites, 3-HB $(p<0.001)$, 3-hydroxypropionic acid $(p<0.001)$, pyroglutamic acid (PG; $p<0.001)$, oxaloacetic acid $(p<0.001)$, eicosadienoic acid $(p<0.001)$, erucic acid $(p<0.005)$, octadecanoic acid $(p<0.006)$, phenylalanine $(p<0.007)$, docosanoic acid $(p<0.012)$, docosahexanoic acid (DHA; $p<0.012)$, tetradecanoic acid $(p<0.013)$, $\alpha$-ketoglutaric acid 
$(p<0.019)$, proline $(p<0.019)$, acetoacetic acid $(p<0.023)$, and tetracosanoic acid $(p<0.023)$ were significantly different in six groups by ANOVA (Table 1, Figure 1, and Supplementary Table S1).
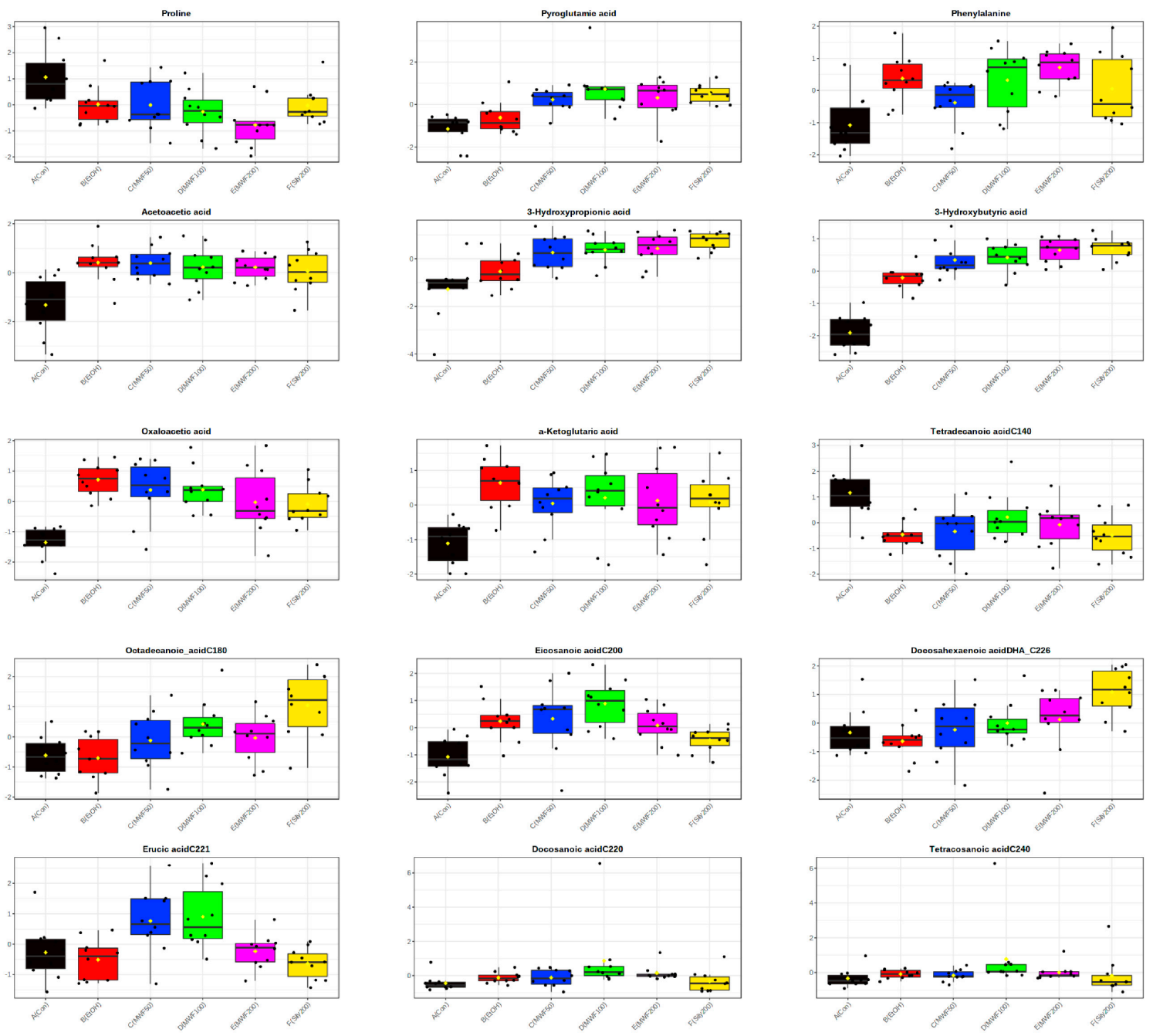

Figure 1. Box plots of 15 significant metabolites in ANOVA. 
Table 1. Levels of 15 significant metabolites in serum from Con, EtOH, MWF50, 100, 200, and Sily200 groups. MWF, mealworm fermentation extract.

\begin{tabular}{|c|c|c|c|c|c|c|c|c|c|c|c|c|c|c|}
\hline \multirow[b]{2}{*}{ No. } & \multirow[b]{2}{*}{ Metabolite } & \multicolumn{6}{|c|}{ Concentration $(\mu \mathrm{g} /$ Serum of $50 \mu \mathrm{L})$} & \multicolumn{5}{|c|}{ Normalized Value $^{\text {a }}$} & \multicolumn{2}{|c|}{$p$-Value ${ }^{\mathrm{b}}$} \\
\hline & & Con & EtOH & $\begin{array}{c}\text { MWF } \\
50\end{array}$ & $\begin{array}{c}\text { MWF } \\
100\end{array}$ & $\begin{array}{l}\text { MWF } \\
200\end{array}$ & $\begin{array}{l}\text { Sily } \\
200\end{array}$ & EtOH & $\begin{array}{c}\text { MWF } \\
50\end{array}$ & $\begin{array}{c}\text { MWF } \\
100\end{array}$ & $\begin{array}{c}\text { MWF } \\
200\end{array}$ & $\begin{array}{l}\text { Sily } \\
200\end{array}$ & ANOVA & FDR $^{c}$ \\
\hline 7 & Proline & $1.65 \pm 0.43$ & $1.28 \pm 0.24$ & $1.28 \pm 0.28$ & $1.20 \pm 0.24$ & $1.07 \pm 0.22$ & $1.27 \pm 0.23$ & 0.78 & 0.78 & 0.73 & 0.65 & 0.77 & 0.005 & 0.019 \\
\hline 9 & Pyroglutamic acid & $0.47 \pm 0.13$ & $0.62 \pm 0.28$ & $0.90 \pm 0.21$ & $1.33 \pm 1.14$ & $0.98 \pm 0.34$ & $1.01 \pm 0.22$ & 1.32 & 1.92 & 2.85 & 2.09 & 2.16 & $<0.001$ & 0.001 \\
\hline 13 & Phenylalanine & $0.67 \pm 0.27$ & $1.15 \pm 0.35$ & $0.85 \pm 0.20$ & $1.16 \pm 0.41$ & $1.30 \pm 0.27$ & $1.07 \pm 0.49$ & 1.73 & 1.28 & 1.74 & 1.95 & 1.60 & 0.001 & 0.007 \\
\hline 17 & Acetoacetic acid & $0.44 \pm 0.27$ & $1.18 \pm 0.61$ & $1.11 \pm 0.45$ & $1.06 \pm 0.55$ & $0.97 \pm 0.29$ & $0.95 \pm 0.46$ & 2.66 & 2.52 & 2.40 & 2.20 & 2.15 & 0.007 & 0.023 \\
\hline 21 & 3-Hydroxypropionic acid & $0.30 \pm 0.14$ & $0.39 \pm 0.12$ & $0.55 \pm 0.18$ & $0.57 \pm 0.14$ & $0.59 \pm 0.16$ & $0.67 \pm 0.11$ & 1.31 & 1.88 & 1.94 & 2.01 & 2.25 & $<0.001$ & 0.001 \\
\hline 22 & 3-Hydroxybutyric acid & $0.26 \pm 0.17$ & $1.67 \pm 0.70$ & $3.53 \pm 2.62$ & $3.58 \pm 1.60$ & $4.59 \pm 1.83$ & $4.79 \pm 1.87$ & 6.48 & 13.67 & 13.87 & 17.77 & 18.53 & $<0.001$ & $<0.001$ \\
\hline 25 & Oxaloacetic acid & $0.02 \pm 0.00$ & $0.06 \pm 0.01$ & $0.05 \pm 0.02$ & $0.05 \pm 0.02$ & $0.04 \pm 0.02$ & $0.04 \pm 0.01$ & 2.62 & 2.36 & 2.30 & 2.03 & 1.82 & $<0.001$ & 0.001 \\
\hline 26 & $\alpha$-Ketoglutaric acid & $0.20 \pm 0.04$ & $0.39 \pm 0.10$ & $0.31 \pm 0.08$ & $0.34 \pm 0.12$ & $0.33 \pm 0.14$ & $0.32 \pm 0.10$ & 1.94 & 1.55 & 1.71 & 1.67 & 1.60 & 0.005 & 0.019 \\
\hline 34 & Tetradecanoic acid $\left(\mathrm{C}_{14: 0}\right)$ & $0.10 \pm 0.03$ & $0.06 \pm 0.01$ & $0.06 \pm 0.02$ & $0.07 \pm 0.02$ & $0.06 \pm 0.02$ & $0.06 \pm 0.01$ & 0.59 & 0.63 & 0.75 & 0.68 & 0.59 & 0.001 & 0.006 \\
\hline 40 & Octadecanoic acid $\left(\mathrm{C}_{18: 0}\right)$ & $7.56 \pm 0.62$ & $7.48 \pm 0.68$ & $8.10 \pm 1.00$ & $8.68 \pm 0.94$ & $8.17 \pm 0.83$ & $9.45 \pm 1.27$ & 0.99 & 1.07 & 1.15 & 1.08 & 1.25 & 0.001 & 0.006 \\
\hline 44 & Eicosanoic acid $\left(\mathrm{C}_{20: 0}\right)$ & $0.03 \pm 0.00$ & $0.03 \pm 0.00$ & $0.03 \pm 0.01$ & $0.04 \pm 0.00$ & $0.03 \pm 0.00$ & $0.03 \pm 0.00$ & 1.18 & 1.20 & 1.28 & 1.15 & 1.08 & $<0.001$ & 0.001 \\
\hline 45 & Docosahexaenoic acid (DHA, $\mathrm{C}_{22: 6}$ ) & $2.32 \pm 0.57$ & $2.12 \pm 0.34$ & $2.41 \pm 0.68$ & $2.52 \pm 0.53$ & $2.65 \pm 0.65$ & $3.36 \pm 0.70$ & 0.91 & 1.04 & 1.09 & 1.14 & 1.45 & 0.002 & 0.012 \\
\hline 47 & Erucic acid $\left(\mathrm{C}_{22: 1}\right)$ & $0.01 \pm 0.01$ & $0.01 \pm 0.00$ & $0.02 \pm 0.01$ & $0.02 \pm 0.01$ & $0.01 \pm 0.00$ & $0.01 \pm 0.00$ & 0.90 & 1.44 & 1.51 & 0.98 & 0.86 & 0.001 & 0.005 \\
\hline 48 & Docosanoic acid $\left(\mathrm{C}_{22: 0}\right)$ & $0.02 \pm 0.00$ & $0.02 \pm 0.00$ & $0.02 \pm 0.00$ & $0.02 \pm 0.01$ & $0.02 \pm 0.00$ & $0.02 \pm 0.00$ & 1.04 & 1.04 & 1.19 & 1.07 & 1.01 & 0.002 & 0.012 \\
\hline 50 & Tetracosanoic acid $\left(\mathrm{C}_{24: 0}\right)$ & $0.02 \pm 0.00$ & $0.02 \pm 0.00$ & $0.02 \pm 0.00$ & $0.02 \pm 0.01$ & $0.02 \pm 0.00$ & $0.02 \pm 0.00$ & 1.04 & 1.03 & 1.25 & 1.05 & 1.04 & 0.003 & 0.013 \\
\hline
\end{tabular}

a Values normalized to corresponding control mean values. ${ }^{\mathrm{b}}$ ANOVA at $95 \%$ confidence level. ${ }^{\mathrm{c}}$ False Discovery Rate. 


\subsection{Star Pattern Recognition Analysis}

Serum AA levels in the six groups at the end of the 8-week study period ranged from 0.65 to 2.85 . Phenylalanine and PG levels were significantly higher in the EtOH group than in the Con group. Serum PG was significantly elevated by MWF at all doses and by silymarin, while phenylalanine was higher in the MWF100 and MWF 200 groups than in the EtOH group. Proline levels were significantly lower in the EtOH group than in the Con group and decreased dose-dependently in the MWF groups. Alteration of OA levels in all groups varied from 0.83 to 18.53. Serum acetoacetic acid, 3-hydroxypropionic acid, 3-HB, oxaloacetic acid, and $\alpha$-ketoglutaric acid were significantly higher in the EtOH group than in the Con group. Of these OAs, acetoacetic, and oxaloacetic acid levels decreased dose-dependently in the MWF groups. However, 3-hydroxypropionic acid and 3-HB levels were increased dose-dependently by MWF groups. Alteration of FFA levels in all groups varied from 0.59 to 1.29. Eicosanoic acid, docosanoic acid, and tetracosanoic acid levels were significantly higher in the EtOH group than in the Con group, whereas tetradecanoic acid levels were significantly lower in the EtOH group than in the Con group and were increased by MWF at all three doses. Octadecanoic acid and DHA were significantly lower in the $\mathrm{EtOH}$ group than in the Con group, and their levels were elevated by MWF (at all doses) and by silymarin groups (Figure 2). 


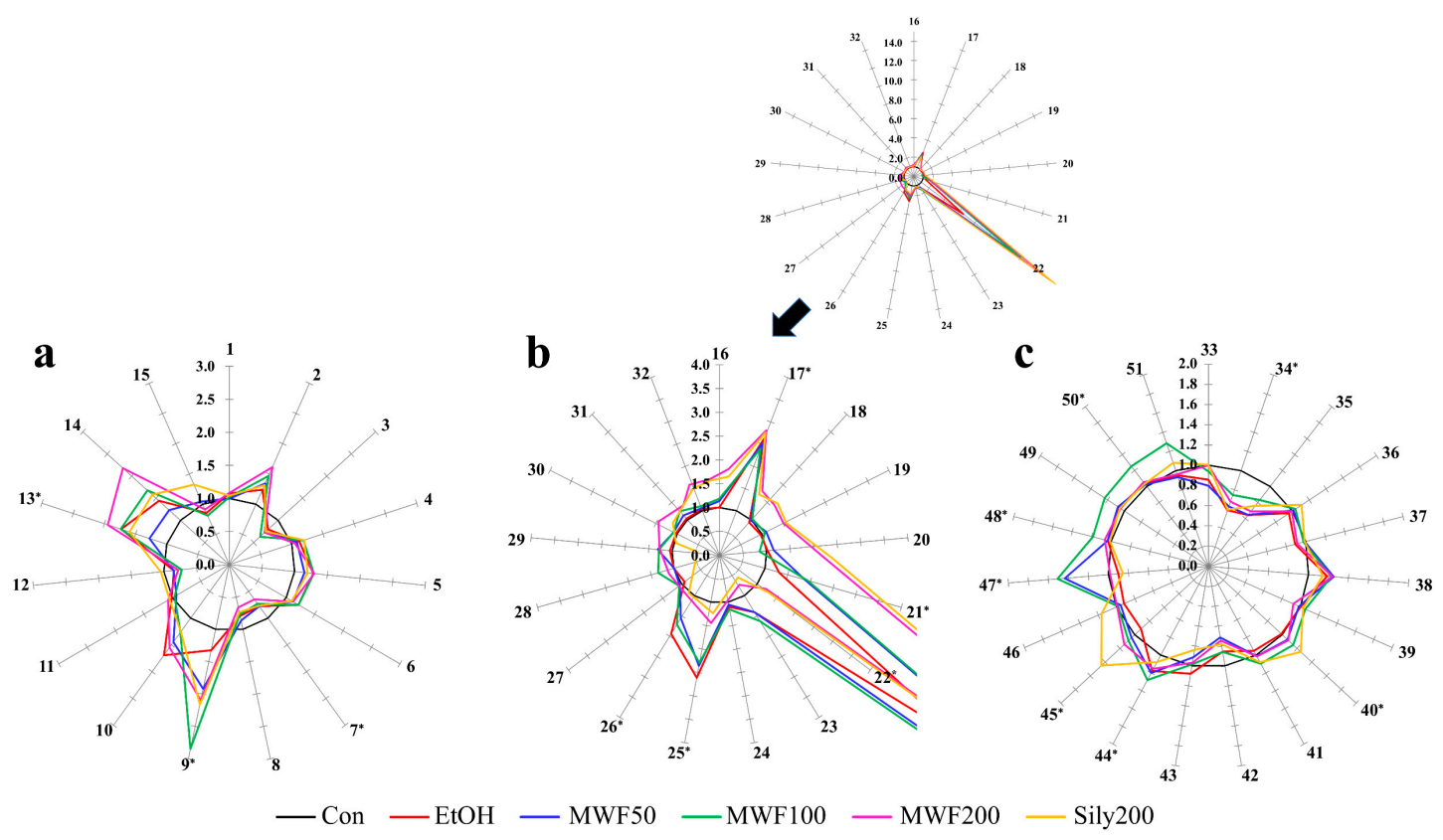

Figure 2. Star symbol plots of (a) amino acids, (b) organic acids, (c) fatty acids in serum for the Con, EtOH, MWF 50, 100, 200, and Sily200 groups mean values. Plots are drawn based on the mean levels of 15 amino acids, 17 organic acids, and 19 fatty acids as the variables after normalization to the corresponding normal mean values. * Significant metabolites in ANOVA. Ray: 1 = Alanine; $2=$ Glycine; $3=\alpha$-Aminobutyric acid; $4=$ Valine; 5 = Leucine; $6=$ Isoleucine; 7 = Proline; 8 = Pipecolic acid; 9 = Pyroglutamic acid; $10=$ Methionine; $11=$ Serine; $12=$ Threonine; 13 = Phenylalanine; $14=$ Aspartic acid; $15=4$-Hydroxyproline; $16=$ Pyruvic acid; $17=$ Acetoacetic acid; 18 = Lactic acid; $19=$ Glycolic acid; $20=2$-Hydroxybutyric acid; $21=3$-Hydroxypropionic acid; 22 = 3-Hydroxybutyric acid; 23 = Succinic acid; $24=$ Fumaric acid; $25=$ Oxaloacetic acid; $26=\alpha$-Ketoglutaric acid; $27=4$-Hydroxyphenylacetic acid; $28=$ Malic acid; $29=2$-Hydroxyglutaric acid; $30=$ cis-Aconitic acid; $31=$ Citric acid; 32 = Isocitric acid; 33 = Dodecanoic acid $\left(\mathrm{C}_{12: 0}\right)$; $34=$ Tetradecanoic acid $\left(\mathrm{C}_{14: 0}\right) ; 35=$ Palmitoleic acid $\left(\mathrm{C}_{16: 1}\right) ; 36=$ Palmitic acid $\left(\mathrm{C}_{16: 0}\right) ; 37=$ $\gamma$-Linolenic acid $\left(\gamma-\mathrm{C}_{18: 3}\right) ; 38=$ Linoleic acid $\left(\mathrm{C}_{18: 2}\right) ; 39=$ Oleic acid $\left(\mathrm{C}_{18: 1}\right) ; 40=$ Octadecanoic acid $\left(C_{18: 0}\right) ; 41=$ Arachidonic acid $\left(C_{20: 4}\right) ; 42=11$-Eicosenic acid $\left(C_{20: 1}\right) ; 43=$ Eicosadienoic acid $\left(\mathrm{C}_{20: 2}\right) ; 44=$ Eicosanoic acid $\left(\mathrm{C}_{20: 0}\right) ; 45=$ Docosahexaenoic acid $\left(\mathrm{DHA}, \mathrm{C}_{22: 6}\right) ; 46=$ Docosatetraenoic acid $\left(C_{22: 4}\right) ; 47=$ Erucic acid $\left(C_{22: 1}\right) ; 48=$ Docosanoic acid $\left(C_{22: 0}\right) ; 49=$ Nervonic acid $\left(C_{24: 1}\right) ; 50=$ Tetracosanoic acid $\left(\mathrm{C}_{24: 0}\right) 51=$ Hexacosanoic acid $\left(\mathrm{C}_{26: 0}\right)$.

\subsection{Multivariate Statistical Analysis}

PCA (unsupervised learning) was performed using PC1 and PC2. The PCA score plot showed unclear separation between the six groups, and the two principle components $(\mathrm{PC} 1=17.1 \%$, PC2 $=12.4 \%$ ) were associated with $29.5 \%$ of total variation (Figure $3 a$ ). However, the Con group and the EtOH group were slightly separated, whereas the Sily200 group and the MWF groups were not separated (Figure 3b). For supervised learning, PLS-DA was performed to identify biomarker candidates. The PLS-DA score plot showed unclear separation between groups with a correlation coefficient (R2) of 0.82 , an accuracy of 0.45 , and a cross-validation correlation coefficient (Q2) of 0.39 . However, the EtOH group and the Sily200 group were slightly separated, and the MWF groups clustered with the Sily200 group (Figure 4b). PCA loading score and variable importance point (VIP) scores of PLS-DA were used to differentiate groups. Of the 51 metabolites, the five top-ranked, that is, leucine (-0.247), PG (-0.237), succinic acid (-0.235), isoleucine $(-0.231)$, and octadecanoic acid $(-0.230)$ were evaluated in the PCA loading score of PC1. Octadecanoic acid (2.524), 3-HB (2.391), 3-hydroxypropionic acid (2.384), PG (2.375), and DHA (1.974) were evaluated with high VIP scores by PLS-DA (Figure $4 \mathrm{a}$ and Table 2). 
$\mathbf{a}$

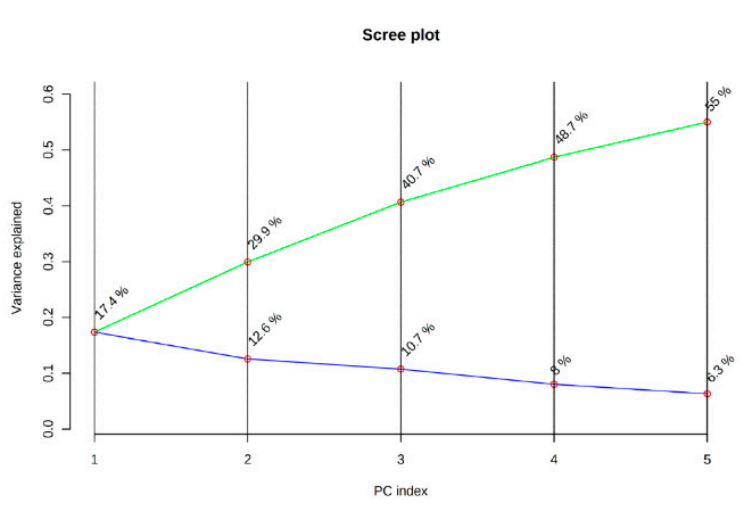

c

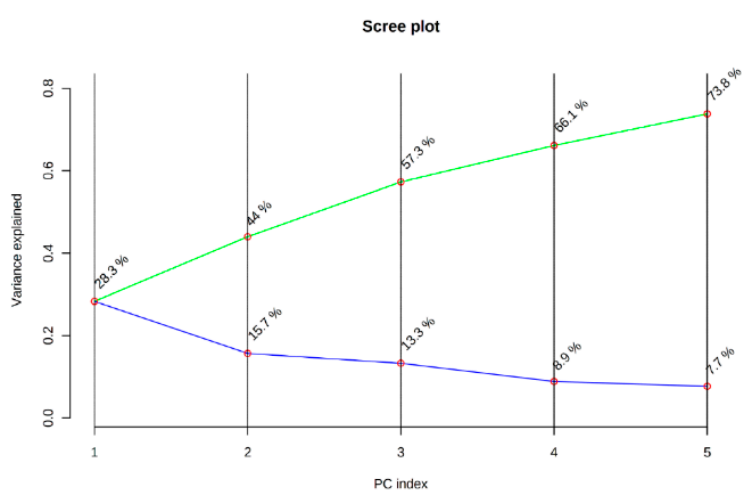

b

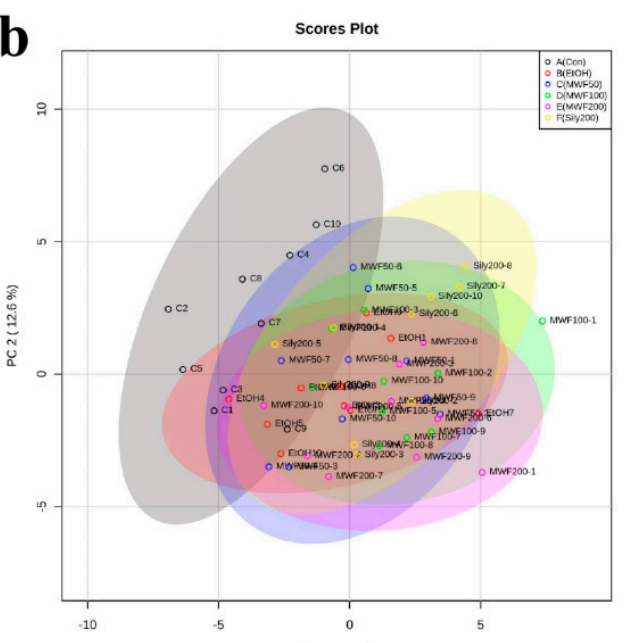

d

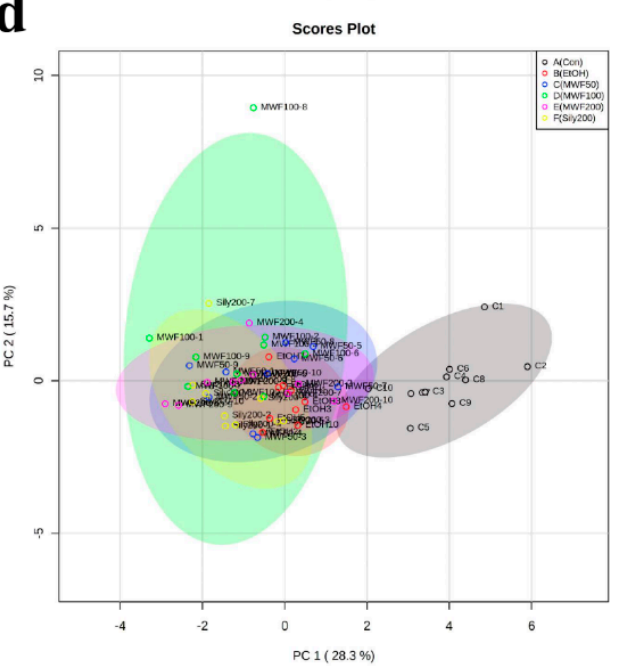

Figure 3. Principal component analysis (PCA) analysis for the Con, EtOH, MWF 50, 100, 200, and Sily200 groups. (a) Scree plot, PCA variance explained; (b) PCA score plot; (c) scree plot, and (d) PCA score plot of significant metabolites in ANOVA. 
Table 2. The PCA loading score and variable importance point (VIP) score of PLS-DA.

\begin{tabular}{|c|c|c|c|c|}
\hline \multirow{3}{*}{ No. } & \multirow{3}{*}{ Metabolite } & \multirow{2}{*}{\multicolumn{2}{|c|}{$\begin{array}{c}\text { Unsupervised Learning } \\
\text { PCA Loading Score }\end{array}$}} & \multirow{3}{*}{$\begin{array}{c}\text { Supervised Learning } \\
\text { PLS-DA } \\
\text { VIP Score }^{a}\end{array}$} \\
\hline & & & & \\
\hline & & PC1 & PC2 & \\
\hline 1 & Alanine & -0.137 & 0.110 & 0.240 \\
\hline 2 & Glycine & -0.043 & 0.314 & 0.557 \\
\hline 3 & $\alpha$-Aminobutyric acid & -0.025 & -0.033 & 0.850 \\
\hline 4 & Valine & -0.219 & -0.187 & 0.828 \\
\hline 5 & Leucine & -0.247 & 0.021 & 0.356 \\
\hline 6 & Isoleucine & -0.231 & -0.101 & 0.185 \\
\hline 7 & Proline & 0.048 & -0.203 & 0.734 \\
\hline 8 & Pipecolic acid & 0.197 & -0.036 & 0.705 \\
\hline 9 & Pyroglutamic acid & -0.237 & -0.002 & 2.375 \\
\hline 10 & Methionine & -0.011 & 0.079 & 0.491 \\
\hline 11 & Serine & 0.034 & 0.203 & 0.365 \\
\hline 12 & Threonine & 0.001 & -0.171 & 0.064 \\
\hline 13 & Phenylalanine & -0.112 & 0.265 & 0.323 \\
\hline 14 & Aspartic acid & -0.047 & 0.280 & 0.008 \\
\hline 15 & 4-Hydroxyproline & 0.002 & -0.167 & 0.707 \\
\hline 16 & Pyruvic acid & -0.100 & 0.003 & 0.615 \\
\hline 17 & Acetoacetic acid & -0.056 & 0.092 & 0.660 \\
\hline 18 & Lactic acid & -0.178 & -0.001 & 0.223 \\
\hline 19 & Glycolic acid & -0.107 & -0.034 & 1.438 \\
\hline 20 & 2-Hydroxybutyric acid & -0.142 & -0.037 & 0.471 \\
\hline 21 & 3-Hydroxypropionic acid & -0.183 & 0.020 & 2.384 \\
\hline 22 & 3-Hydroxybutyric acid & -0.194 & 0.124 & 2.391 \\
\hline 23 & Succinic acid & -0.235 & 0.047 & 1.114 \\
\hline 24 & Fumaric acid & -0.193 & 0.115 & 0.147 \\
\hline 25 & Oxaloacetic acid & -0.205 & 0.115 & 0.334 \\
\hline 26 & $\alpha$-Ketoglutaric acid & -0.216 & 0.058 & 0.233 \\
\hline 27 & 4-Hydroxyphenylacetic acid & 0.014 & 0.049 & 0.080 \\
\hline 28 & Malic acid & -0.174 & 0.160 & 0.572 \\
\hline 29 & 2-Hydroxyglutaric acid & -0.146 & 0.078 & 0.988 \\
\hline 30 & cis-Aconitic acid & -0.051 & 0.093 & 1.083 \\
\hline 31 & Citric acid & -0.092 & 0.164 & 0.650 \\
\hline 32 & Isocitric acid & -0.096 & 0.153 & 0.569 \\
\hline 33 & Dodecanoic acid $\left(\mathrm{C}_{12: 0}\right)$ & -0.016 & -0.064 & 0.463 \\
\hline 34 & Tetradecanoic acid $\left(\mathrm{C}_{14: 0}\right)$ & 0.046 & -0.079 & 0.695 \\
\hline 35 & Palmitoleic acid $\left(\mathrm{C}_{16: 1}\right)$ & 0.080 & -0.184 & 0.143 \\
\hline 36 & Palmitic acid $\left(\mathrm{C}_{16: 0}\right)$ & 0.113 & -0.155 & 1.812 \\
\hline 37 & $\gamma$-Linolenic acid $\left(\gamma-C_{18: 3}\right)$ & -0.180 & -0.249 & 0.935 \\
\hline 38 & Linoleic acid $\left(\mathrm{C}_{18: 2}\right)$ & -0.061 & -0.135 & 0.514 \\
\hline 39 & Oleic acid $\left(\mathrm{C}_{18: 1}\right)$ & -0.115 & -0.097 & 0.522 \\
\hline 40 & Octadecanoic acid $\left(\mathrm{C}_{18: 0}\right)$ & -0.230 & -0.184 & 2.524 \\
\hline 41 & Arachidonic acid $\left(\mathrm{C}_{20: 4}\right)$ & -0.210 & -0.115 & 1.359 \\
\hline 42 & 11 -Eicosenic acid $\left(\mathrm{C}_{20: 1}\right)$ & -0.081 & -0.220 & 0.351 \\
\hline 43 & Eicosadienoic acid $\left(\mathrm{C}_{20: 2}\right)$ & -0.099 & -0.240 & 0.859 \\
\hline 44 & Eicosanoic acid $\left(\mathrm{C}_{20: 0}\right)$ & -0.186 & -0.192 & 0.569 \\
\hline 45 & $\begin{array}{c}\text { Docosahexaenoic acid } \\
\left(\text { DHA, } C_{22: 6}\right)\end{array}$ & -0.180 & 0.007 & 1.974 \\
\hline 46 & Docosatetraenoic acid $\left(\mathrm{C}_{22: 4}\right)$ & -0.145 & -0.131 & 1.129 \\
\hline 47 & Erucic acid $\left(C_{22: 1}\right)$ & -0.103 & -0.163 & 0.835 \\
\hline 48 & Docosanoic acid $\left(C_{22: 0}\right)$ & -0.093 & -0.038 & 0.550 \\
\hline 49 & Nervonic acid $\left(C_{24: 1}\right)$ & -0.083 & 0.042 & 0.620 \\
\hline 50 & Tetracosanoic acid $\left(\mathrm{C}_{24: 0}\right)$ & -0.058 & 0.004 & 0.575 \\
\hline 51 & Hexacosanoic acid $\left(C_{26: 0}\right)$ & 0.030 & 0.015 & 0.532 \\
\hline
\end{tabular}


$\mathbf{a}$

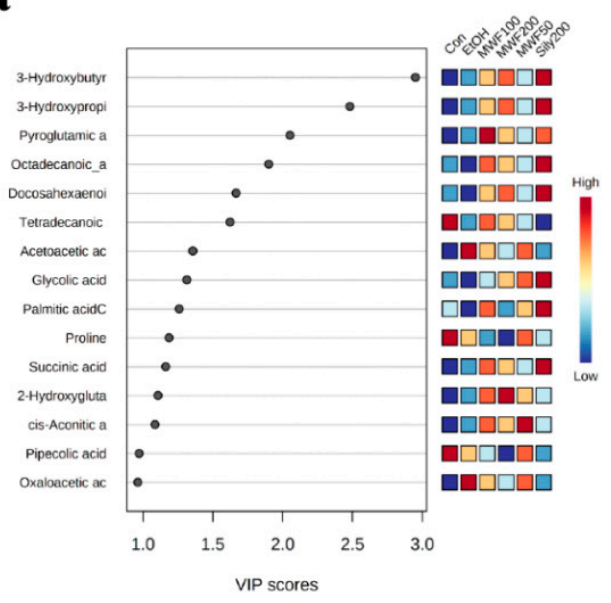

c

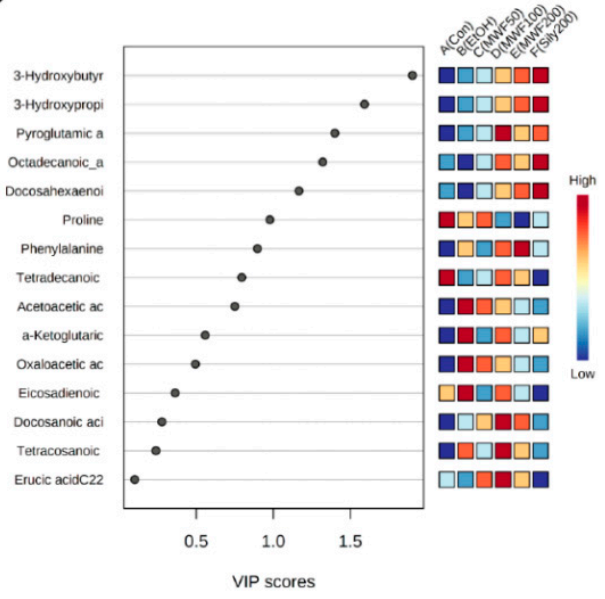

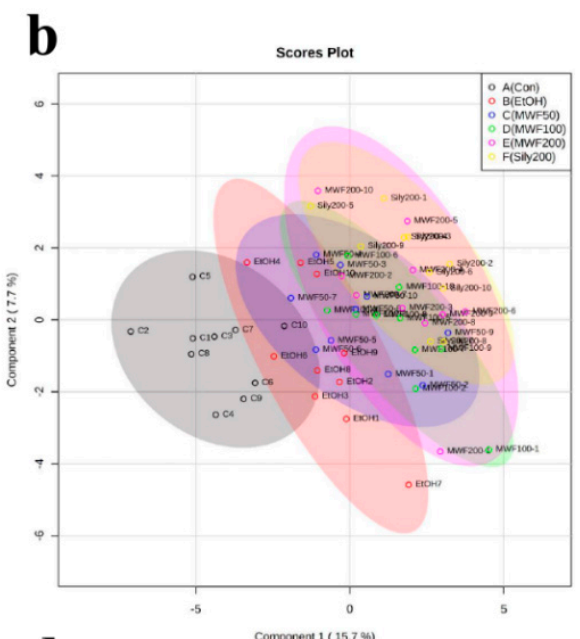
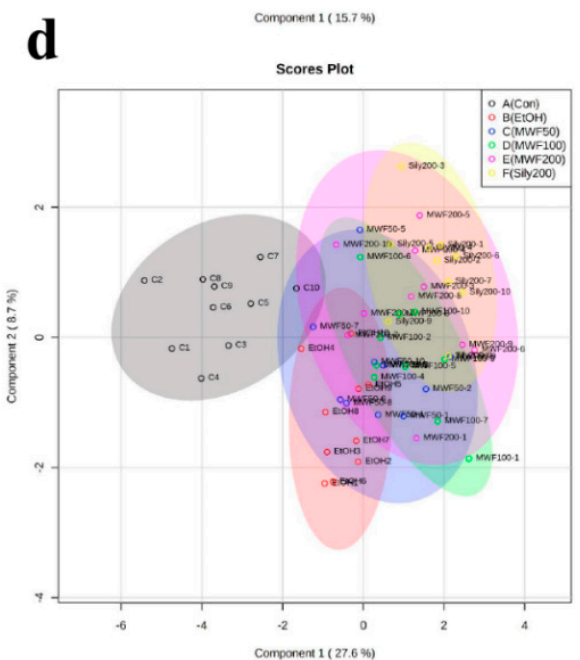

Figure 4. Partial least squares discriminant analysis (PLS-DA) analysis for the Con, EtOH, MWF 50, 100, 200, and Sily200 groups. (a) PLS-DA score plot; (b) variable importance analysis of top 15 metabolites; (c) PLS-DA score plot of significant metabolites in ANOVA; (d) variable importance analysis of top 15 metabolites, metabolites that are significant changes in ANOVA.

\section{Discussion}

We previously demonstrated that MWF ameliorated ALD by reducing gene expression associated with triglyceride and cholesterol synthesis and protein expression associated with the nuclear factor- $\mathrm{kB}$ pathway, as well as increasing hepatic glutathione (GSH) content in chronic alcohol-fed rats [8]. The MWF has more free amino acid contents than non-fermentation (data not shown). The most abundant amino acids of MWF were glutamic acid, leucine, and alanine, which were known to have therapeutic effects against liver disease [13,23-26]. Therefore, in this study, we monitored metabolic changes related to the hepatoprotective effect of MWF by performed profiling analyses on serum OAs, AAs, and FFAs.

We found that the metabolite most changed by alcohol consumption was 3-HB, which was higher in the EtOH group than in the Con group. 3-HB is a ketone body, and ketone bodies are produced predominantly in the hepatic mitochondrial matrix from $\beta$-oxidation-derived acetyl-CoA and serve as energy sources in extrahepatic tissues [27]. A previous study reported that 3-HB ( $3 \mathrm{mmol} / \mathrm{kg}$, intraperitoneal injection) could protect against acute alcoholic hepatitis by enhancing the expression of the anti-inflammatory IL-10 gene and enhancing the M2 phenotype of hepatic macrophages [28]. In this study, the 3-HB level of MWF (50, 100, and $200 \mathrm{mg} / \mathrm{kg}$ ) and silymarin $(200 \mathrm{mg} / \mathrm{kg})$ dose-independently was elevated by compared with the EtOH group by 2.1-, 2.1-, 2.7-, 2.9-fold, respectively. Ajmo et al. [29] reported that resveratrol increased 3-HB levels, which were 
increased by alcohol. The authors considered this increase might induce fatty acid oxidation and lead to ketone body production. Li et al. [30] showed that $\mathrm{EtOH}$ administration with dietary nicotinic acid supplementation increased serum 3-HB levels compared with the alcohol supplementation group, indicating that an elevated hepatic $\mathrm{NAD}^{+}$level led to mitochondrial fatty acid $\beta$-oxidation. Our results showed that hepatic $\beta$-oxidation activity in the MWF groups (MWF50: $3.185 \pm 0.484$; MWF100: $4.517 \pm 0.529$; MWF200: $5.737 \pm 0.788 \mathrm{nmol} / \mathrm{min} / \mathrm{mg}$ protein) were dose-dependently increased as compared with the EtOH group $(3.061 \pm 0.455 \mathrm{nmol} / \mathrm{min} / \mathrm{mg}$ protein; Supplementary Figure S1). Moreover, the Sily200 group ( $5.474 \pm 0.533 \mathrm{nmol} / \mathrm{min} / \mathrm{mg}$ protein) had activity similar to the MWF200 group. These results indicate increased 3-HB production by MWF may reflect the greater $\beta$-oxidation activity.

In this study, eight OAs related to tricarboxylic acid (TCA) cycle were up-regulated in alcohol-fed rats, and in particular, oxaloacetic acid and $\alpha$-ketoglutaric acid levels increased significantly. Citric acid, cis-aconitic acid, isocitric acid, succinic acid, fumaric acid, and malic acid levels also showed increasing tendencies in the MWF100 and MWF200 groups as compared with the EtOH group, probably due to increased TCA cycle activity. However, the oxaloacetic acid level was dose-dependently reduced, and the $\alpha$-ketoglutaric acid level was dose-independently decreased by the MWF, which were similar to those of the silymarin. Interestingly, serum liver damage markers, AST and ALT activities showed a positive correlation with oxaloacetic acid (AST; $r=0.618, p<0.01$, ALT; $r=0.478, p<0.01$ ) and $\alpha$-ketoglutaric acid (AST; $r=0.586, p<0.01$, ALT; $r=0.508, p<0.01$ ). The previous study reported that plasma $\alpha$-ketoglutaric acid could act as a predictor in morbidly obese patients with fatty liver disease [31]. These results indicated that the decrease of oxaloacetic acid and $\alpha$-ketoglutaric acid in serum by MWF might be associated with the decrease of AST and ALT.

A recent study suggests that potential pathways associated with alcoholic liver injury, including the D-glutamine, D-glutamate, cysteine, and methionine metabolisms in the liver [16]; but we did not find the same metabolisms in the serum, which may be because the serum or tissues, animal species, alcohol dose, and duration were different. In the present study, chronic alcohol consumption was elevated PG levels compared to the Con group about 1.3-fold, however, MWF (50, 100, and $200 \mathrm{mg} / \mathrm{kg}$ ) or silymarin $(200 \mathrm{mg} / \mathrm{kg})$ supplementation were further increased PG levels by 1.5-, 2.2-, 1.6-, 1.6-fold, respectively, compared with the EtOH group. PG is an intermediate metabolite of the $\gamma$-glutamyl cycle and is converted into glutamate, which resynthesizes GSH using ATP-dependent enzymes, including glutamate cysteine ligase and GSH synthase [32]. Interestingly, the PG of human placental extracts has been reported to promote liver regeneration by inducing DNA synthesis in rat primary hepatocytes via the mitogen-activated protein kinase (MAPK) pathway [33]. Since PG is more stable than glutamine or glutamic acid, it is used in care products that increase GSH production [34]. Metadoxine, which consists of PG and vitamin B6, appears to be effective at treating acute alcohol intoxication and for improving liver function following chronic alcoholism [35]. Serum glycine contents were higher in all three MWF and silymarin groups than in the $\mathrm{EtOH}$ group. Glycine is the final precursor amino acid required for GSH synthesis and binds to $\gamma$-glutamylcysteine to form GSH [36]. We previously found that alcohol consumption significantly reduced hepatic GSH contents and that MWF supplementation to alcohol-administered rats effectively increased hepatic GSH contents to more than that observed in the Con group [8]. GSH is a non-enzymatic antioxidant and a redox regulator in cells [36]. It is a tripeptide composed of glutamate, cysteine, and glycine [37], and plays a key role in the detoxifications of reactive oxygen species, reactive nitrogen species, and xenobiotics in cells [38]. Although we did not observe a relation between serum PG and hepatic GSH levels in the present study, our results suggest that MWF or silymarin supplementation up-regulate GSH synthesis by increasing the level of PG, a precursor of glutamate. Another previous study reported that valine, leucine, and phenylalanine levels were significantly increased in the serum following chronic alcohol intake, while they were slightly increased in our result [39].

Serum FFA metabolic profiles revealed that MWF (dose-dependent manner) and silymarin significantly increased serum DHA levels that were decreased by alcohol. Interestingly, both $n-3$ 
and n-6 polyunsaturated fatty acids (PUFAs) are components of cell membranes and precursors of biologically active substances [40], and PUFAs deficiency is commonly found in patients with ALD [41]. A previous study reported that dietary DHA attenuated alcohol-induced hepatosteatosis by down-regulating lipogenesis and inflammatory cytokine levels [42]. N-3 PUFAs can inhibit inflammatory mediators, such as protein kinases (c-jun N-terminal kinases, MAPK, p38), nuclear factor $\kappa B$, and cytokines (tumor necrosis factor- $\alpha$, interleukin (IL) $-1 \beta, \mathrm{IL}-6$, etc.), and reduce lipid biosynthesis by down-regulating sterol regulatory element binding protein $1 \mathrm{c}$ in several metabolic diseases [43]. Wang et al. [40] demonstrated that n-3 PUFAs, including DHA and eicosapentaenoic acid (EPA), alleviated ALD by reducing FFA uptake from adipose tissue by the liver. In the present study, long-chain saturated FFA serum levels, including palmitic acid and octadecanoic acid, were lower in the EtOH group than in the Con group, and MWF (at all doses) and silymarin increased these levels. In our previous study, hepatic FFA uptake-related gene expressions (fatty acid transport protein 5 (FATP5) and a cluster of differentiation [36]) were greater in the $\mathrm{EtOH}$ group than in the Con group, while MWF tended to reduce these expressions and silymarin significantly reduced FATP5 expression [8]. We speculate that MWF and silymarin inhibited FFAs influx into the liver, and that this increased serum FFA levels. Consequently, increased DHA levels in the MWF and silymarin groups appeared to protect alcohol-fed rats from inflammation and steatosis.

The current study was performed based on a targeted metabolomics approach of 51 metabolites rather than full metabolite analysis in ALD. In this metabolomics results, metabolic change of MWF showed a similar pattern to the metabolism of silymarin with a hepatoprotective effect in a rat model with alcoholic liver injury. In the previous study, we reported for the hepatoprotective effect of MWF [8]. Thus, the present metabolomics results may explain for the efficacy of MWF in the liver after alcohol intake. In further study, comprehensive metabolomics analysis for various metabolites with large samples in liver tissues is necessary for biomarker detection and understanding of altered metabolism related to the efficacy of MWF.

\section{Materials and Methods}

\subsection{Chemicals and Reagents}

AA standards, OA standards, FFA standards, internal standards (IS; norvaline, ${ }^{13} \mathrm{C}_{1}$-leucine, ${ }^{13} \mathrm{C}_{1}$-phenylalanine, ${ }^{13} \mathrm{C}_{2}$-succinic acid, 3,4-dimethoxybenzoic acid, and lauric- $\mathrm{d}_{2}$-acid), ethyl chloroformate (ECF), and triethylamine (TEA) were purchased from Sigma-Aldrich (St. Louis, MO, USA). $N$-Methyl-N-tert-butyldimethylsilyl trifluoroacetamide (MTBSTFA) was obtained from Pierce (Rockford, IL, USA). Diethyl ether, ethyl acetate, toluene, and dichloromethane were purchased from Kanto Chemical Co. Inc. (Chuoku, Tokyo, Japan), and other reagents, including sulfuric acid, sodium hydroxide, and sodium chloride, were manufactured by Deajung (Gyeongido, Korea). All chemicals were analytical reagent grade.

\subsection{Preparation of Serum from ALD Rat Model}

Serum for GC-MS/MS analysis was acquired from ALD rats, as previously described [8]. Sprague-Dawley rats (4-week-old, males) were obtained from Orient Bio Inc. (Seoul, Korea). Rats were housed individually in stainless-steel cages in a controlled room $\left(20 \pm 2{ }^{\circ} \mathrm{C}\right.$ and $50 \pm 5 \%$ humidity) under a $12 \mathrm{~h}$ light-dark cycle. Animals were fed a chow diet and water ad libitum. After two weeks of acclimatization, they were divided into six groups of ten rats, as follows; (1) Con, an isocaloric normal liquid diet, (2) EtOH, an alcohol liquid diet, (3) MWF50, the alcohol liquid diet plus $50 \mathrm{mg} \mathrm{MWF} / \mathrm{kg}$ BW/day, (4) MWF100, the alcohol liquid diet plus $100 \mathrm{mg} \mathrm{MWF/kg} \mathrm{BW/day,} \mathrm{(5)} \mathrm{MWF200,} \mathrm{the} \mathrm{alcohol}$ liquid diet plus $200 \mathrm{mg} \mathrm{MWF/kg} \mathrm{BW/day,} \mathrm{(6)} \mathrm{Sily200} \mathrm{(positive} \mathrm{control),} \mathrm{the} \mathrm{alcohol} \mathrm{liquid} \mathrm{diet} \mathrm{plus}$ $200 \mathrm{mg}$ of silymarin (Sigma-Aldrich, Co., St. Louis, MO, USA)/kg BW/day. The silymarin has been used as a hepatoprotective agent to treat liver disease in Asia, Southern Europe, and America [44]. Liquid diets were based on the Lieber-DeCarli formulation and provided $1 \mathrm{kcal} / \mathrm{mL}$. MWF or silymarin 
was dissolved in distilled water and given orally once a day, while the Con and EtOH groups were administered with distilled water. The experimental period lasted for eight weeks. Blood samples were collected from the inferior vena cava at the end of the experimental period. Serum was obtained by centrifugation $\left(3000 \mathrm{rpm}, 15 \mathrm{~min}, 4{ }^{\circ} \mathrm{C}\right.$ ) and stored at $-80{ }^{\circ} \mathrm{C}$ until analysis. Animal care and the protocols used were approved by The Sunchon National University Institutional Animal Care and Use Committee (SCNU_IACUC-2018-12).

\subsection{Gas Chromatography-Tandem Mass Spectrometry (GC-MS/MS)}

GC-MS/MS analyses of AAs, OAs, and FFAs were performed using a GCMS-TQ8040 interfaced with a triple quadrupole mass spectrometer (Shimadzu Corp., Kyoto, Japan) in electron impact mode at $70 \mathrm{eV}$. The column used was an Ultra $-2(25 \mathrm{~m} \times 0.20 \mathrm{~mm}$ I.D., $0.11 \mu \mathrm{m}$ film thickness $)$ capillary column (Agilent Technologies, Santa Clara, CA, USA). Ion source, injector, and interface temperatures were 230,260 , and $300{ }^{\circ} \mathrm{C}$, respectively. Helium was used as the carrier gas at a constant flow rate of $0.5 \mathrm{~mL} / \mathrm{min}$. Samples $(1 \mu \mathrm{L})$ were injected in split-injection mode (10:1). For AA analysis, the oven temperature was programmed as follows; $140{ }^{\circ} \mathrm{C}$ for $3 \mathrm{~min}, 140{ }^{\circ} \mathrm{C}$ to $300{ }^{\circ} \mathrm{C}$ at a rate of $8{ }^{\circ} \mathrm{C} \mathrm{min}$, and $300^{\circ} \mathrm{C}$ for $5 \mathrm{~min}$. For OA and FFA analyses, the following program was used; $100{ }^{\circ} \mathrm{C}$ for $2 \mathrm{~min}$, $100{ }^{\circ} \mathrm{C}$ to $250{ }^{\circ} \mathrm{C}$ at $10{ }^{\circ} \mathrm{C} / \mathrm{min}, 250^{\circ} \mathrm{C}$ to $300{ }^{\circ} \mathrm{C}$ at $20^{\circ} \mathrm{C} / \mathrm{min}$, and $300{ }^{\circ} \mathrm{C}$ for $5 \mathrm{~min}$.

\subsection{Sample Preparation for Serum AA Profiling Analysis}

Profiling analysis of AAs was performed by GC-MS using ethoxylcarbonyl (EOC)-tert-butyldimethylsilyl (TBDMS) derivatives, as previously described [21,45]. Briefly, proteins were removed using acetonitrile to $50 \mu \mathrm{L}$ of serum containing norvaline, ${ }^{13} \mathrm{C}_{1}$-leucine, and ${ }^{13} \mathrm{C}_{1}$-phenylalanine as ISs $(0.2,0.4$, and $0.5 \mu \mathrm{g}$, respectively). After centrifugation, the supernatant was spiked into deionized water $(1 \mathrm{~mL})$, dichloromethane $(2.0 \mathrm{~mL})$ containing ECF $(20 \mu \mathrm{L})$ was added, and the $\mathrm{pH}$ was adjusted to $\geq 12$ with $5.0 \mathrm{M}$ sodium hydroxide. The two-phase EOC reaction was performed with vortexing for $10 \mathrm{~min}$. The $\mathrm{pH}$ was then adjusted to $\leq 2$ with $10 \% \mathrm{H}_{2} \mathrm{SO}_{4}$, and the mixture was saturated with sodium chloride and sequentially extracted with diethyl ether $(3 \mathrm{~mL})$ and ethyl acetate $(2 \mathrm{~mL})$. Extracts were evaporated to dryness under a gentle stream of nitrogen $\left(40^{\circ} \mathrm{C}\right)$. Prior to GC-MS/MS analysis, TBDMS derivatives were produced in toluene $(15 \mu \mathrm{L})$, MTBSTFA $(20 \mu \mathrm{L})$, and TEA $(5 \mu \mathrm{L})$ mixture for $1 \mathrm{~h}$ at $60^{\circ} \mathrm{C}$. Derivatives were transferred to an auto vial and analyzed directly by GC-MS/MS in multiple reaction monitoring (MRM) mode.

\subsection{Sample Preparation for Serum OA Profiling Analysis}

Profiling analysis of OAs was performed using methoxime (MO)-TBDMS derivatives by GC-MS, as previously described [21,46]. Briefly, proteins were removed using acetonitrile to $50 \mu \mathrm{L}$ of serum containing ${ }^{13} \mathrm{C}_{2}$-succinic acid, 3,4-dimethoxybenzoic acid as ISs (0.5 and $\left.0.1 \mu \mathrm{g}\right)$. After centrifugation, the supernatants were spiked into deionized water $(1 \mathrm{~mL})$, methoxyamine hydrochloride $(1 \mathrm{mg})$ was then added, and $\mathrm{pH}$ was adjusted to $\geq 12$ with $5.0 \mathrm{M}$ sodium hydroxide. $\mathrm{MO}$ derivatives for carbonyl groups of OAs were produced by reacting at $60^{\circ} \mathrm{C}$ for $1 \mathrm{~h}$. After the $\mathrm{MO}$ reaction, $\mathrm{pH}$ was adjusted to $\mathrm{pH} \leq 2$ with $10 \% \mathrm{H}_{2} \mathrm{SO}_{4}$, and the mixture saturated with sodium chloride and sequentially extracted using diethyl ether $(3 \mathrm{~mL})$ and ethyl acetate $(2 \mathrm{~mL})$. TEA $(5 \mu \mathrm{L})$ was then added to extracts, which were then evaporated to dryness under a gentle stream of nitrogen $\left(40^{\circ} \mathrm{C}\right)$. Prior to GC-MS/MS analysis, TBDMS derivatives were produced in a toluene $(10 \mu \mathrm{L})$ and MTBSTFA $(20 \mu \mathrm{L})$ mixture for $60 \mathrm{~min}$ at $60{ }^{\circ} \mathrm{C}$. Derivatives were transferred to auto vials and analyzed directly by GC-MS/MS in MRM mode.

\subsection{Sample Preparation for Serum FFA Profiling Analysis}

Profiling analysis of FFAs was performed by GC-MS of TBDMS derivatives, as previously described [21,47]. Briefly, proteins were removed using acetonitrile to $50 \mu \mathrm{L}$ of serum containing lauric- $\mathrm{d}_{2}$-acid as IS $(0.1 \mu \mathrm{g})$. After centrifugation, the supernatant was spiked into deionized water (1 mL), adjusted to $\mathrm{pH} \leq 2$ with $10 \% \mathrm{H}_{2} \mathrm{SO}_{4}$, saturated with sodium chloride, and sequentially extracted 
using diethyl ether $(3 \mathrm{~mL})$ and ethyl acetate $(2 \mathrm{~mL})$. TEA $(5 \mu \mathrm{L})$ was added to extracts and evaporated to dryness under a gentle stream of nitrogen $\left(40^{\circ} \mathrm{C}\right)$. Prior to GC-MS/MS analysis, TBDMS derivatives were produced in a toluene $(10 \mu \mathrm{L})$ and MTBSTFA $(20 \mu \mathrm{L})$ mixture for $60 \mathrm{~min}$ at $60^{\circ} \mathrm{C}$. Derivatives were transferred to auto vials and analyzed directly by GC-MS/MS in MRM mode.

\subsection{Star Pattern Recognition Analysis and Statistical Analysis}

Levels of the 51 metabolites in rat serum were determined using calibration curves. The amount mean levels in the five experimental groups were normalized versus the Con group. Star graph was drawn using Microsoft Excel (2010) using normalized mean values [20,21]. ANOVA was used to determine the significances of intergroup differences in metabolite levels. ANOVA was conducted using IBM SPSS Statistics 20 (IBM Corporation, Armonk, NY). Multivariate statistical analysis was performed by PCA (unsupervised learning) and PLS-DA (supervised learning). PCA was used to detect data trends and pattern analyses. PLS-DA was used to search for biomarker candidates that differentiated the Con, $\mathrm{EtOH}, \mathrm{MWF}$, and silymarin groups. Multivariate analyses were performed using log 10-transformed, mean-centered, and auto-scaled data using Metaboanalyst (https://www.metaboanalyst.ca). The validity of the PLS-DA model was verified using correlation coefficients $\left(R_{2}\right)$ and cross-validation correlation coefficients $\left(\mathrm{Q}_{2}\right)$.

\section{Conclusions}

Various statistical approaches were used to identify metabolites that differentiated the six study groups. 3-HB, PG, octadecanoic acid, and DHA were found to have high VIP, and PCA loading scores by PLS-DA and PCA, and their levels were significantly higher in the MWF and silymarin groups than in the EtOH group. We suggest the protective effects of MWF on alcohol-induced liver injury are associated with these 3-HB, PG, octadecanoic acid, and DHA increases and may be mediated by regulations of $\beta$-oxidation activity, inflammation, GSH production, and liver FFA uptake (Figure 5). We believe the present metabolomic study will be useful for monitoring the effectiveness of MWF treatment in alcohol-fed rats.

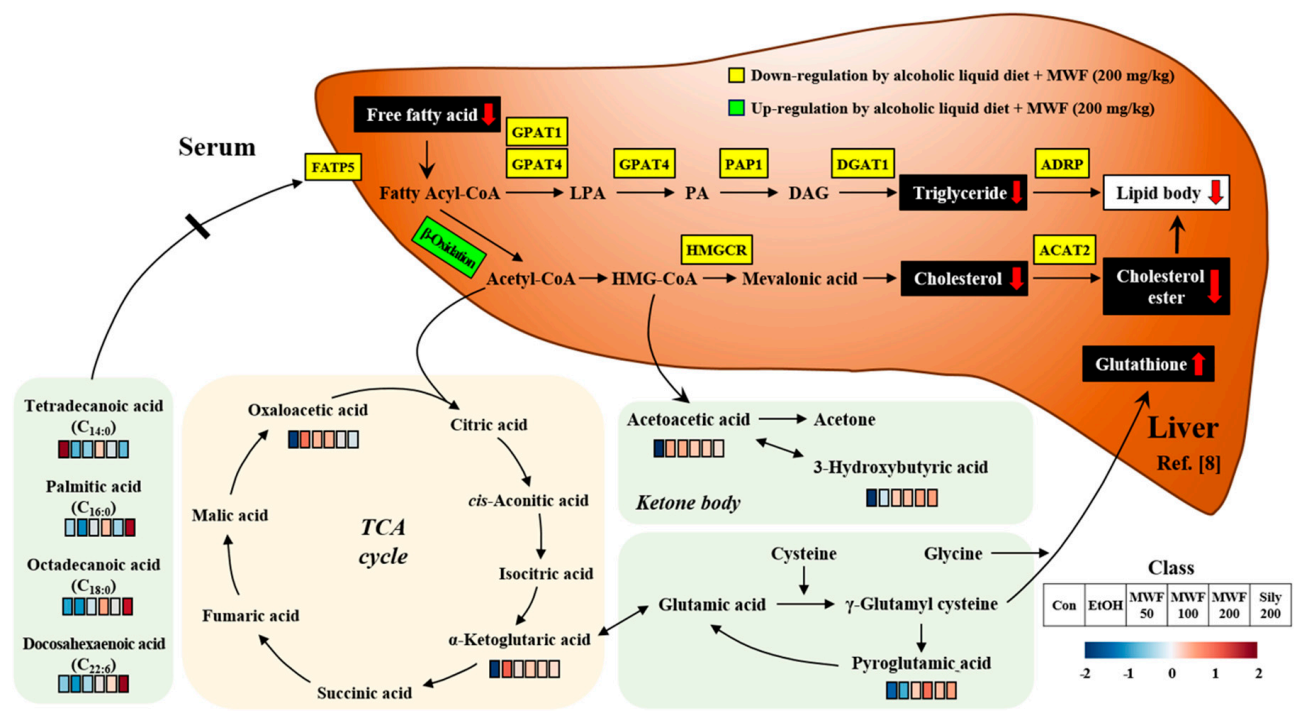

Figure 5. Predicted association indicating key findings of MWF from serum metabolic profiling and hepatic molecular mechanism in chronic alcohol-fed rats [8]. The red bars indicate an increased level of metabolite compared to the Con group. The blue bars indicate a reduced level of metabolite compared to the Con group. The white bars indicate no significant differences of metabolite between the treated-group and the Con group. Levels of altered metabolites showed in Table 1 and Supplementary Table S1. 
Supplementary Materials: The following are available online at http://www.mdpi.com/2218-1989/10/11/436/s1, Figure S1: Effects of MWF on the hepatic $\beta$-oxidation activity in chronic alcohol-fed rats, Table S1: Levels of metabolites in serum from con, EtOH, MWF-50, 100, 200, and sily200 groups.

Author Contributions: M.-K.L. and M.-J.P. designed rat model and metabolomics study and supervised this experiment. Experiments were performed by R.-Y.C. for rat model and M.J. for metabolite profiling analysis. M.J., R.-Y.C., M.-K.L. and M.-J.P. contributed to data interpretation. R.-Y.C. and M.J. contributed to drafting the manuscript. M.-K.L. and M.-J.P. revised for manuscript. All authors have read and agreed to the published version of the manuscript.

Funding: This research received no external funding.

Acknowledgments: This research was supported by the Ministry of Trade, Industry \& Energy (MOTIE), Korea Institute for Advancement of Technology (KIAT) through the Encouragement Program for The Industries of Economic Cooperation Region (P0000833).

Conflicts of Interest: The authors have no conflict of interest to declare.

\section{References}

1. Sousa, P.; Borges, S.; Pintado, M. Enzymatic Hydrolysis of Insect Alphitobius diaperinus towards the Development of Bioactive Peptide Hydrolysates. Food Funct. 2020, 11, 3539-3548. [CrossRef] [PubMed]

2. De Marco, M.; Martínez, S.; Hernandez, F.; Madrid, J.; Gai, F.; Rotolo, L.; Belforti, M.; Bergero, D.; Katz, H.; Dabbou, S.; et al. Nutritional Value of Two Insect Larval Meals (Tenebrio molitor and Hermetia illucens) for Broiler Chickens: Apparent Nutrient Digestibility, Apparent Ileal Amino Acid Digestibility and Apparent Metabolizable Energy. Anim. Feed Sci. Technol. 2015, 209, 211-218. [CrossRef]

3. Seo, M.; Goo, T.W.; Chung, M.Y.; Baek, M.; Hwang, J.S.; Kim, M.A.; Yun, E.Y. Tenebrio molitor Larvae Inhibit Adipogenesis through AMPK and MAPKs Signaling in 3T3-L1 Adipocytes and Obesity in High-Fat Diet-Induced Obese Mice. Int. J. Mol. Sci. 2017, 18, 518. [CrossRef] [PubMed]

4. Kim, G.H.; Baek, H.K.; Lee, J.S.; Kim, S.J.; Yi, S.S. Chronic Oral Administration of Tenebrio molitor Extract Exhibits Inhibitory Effect on Glucocorticoid Receptor Overexpression in the Hippocampus of Ovariectomy-Induced Estrogen Deficient Mice. J. Food Sci. 2019, 84, 687-694. [CrossRef] [PubMed]

5. del Hierro, J.N.; Gutiérrez-Docio, A.; Otero, P.; Reglero, G.; Martin, D. Characterization, Antioxidant Activity, and Inhibitory Effect on Pancreatic Lipase of Extracts from the Edible Insects Acheta domesticus and Tenebrio molitor. Food Chem. 2020, 309, 125742. [CrossRef]

6. Pessina, F.; Frosini, M.; Marcolongo, P.; Fusi, F.; Saponara, S.; Gamberucci, A.; Valoti, M.; Giustarini, D.; Fiorenzani, P.; Gorelli, B.; et al. Antihypertensive, Cardio-and Neuro-Protective Effects of Tenebrio molitor (Coleoptera: Tenebrionidae) Defatted Larvae in Spontaneously Hypertensive Rats. PLoS ONE 2020, 15, e0233788. [CrossRef]

7. Cho, H.R.; Lee, S.O. Novel Hepatoprotective Peptides Derived from Protein Hydrolysates of Mealworm (Tenebrio molitor). Food Res. Int. 2020, 133, 109194. [CrossRef]

8. Choi, R.Y.; Ham, J.R.; Ryu, H.S.; Lee, S.S.; Miguel, M.A.; Paik, M.J.; Ji, M.; Park, K.W.; Kang, K.Y.; Lee, H.I.; et al. Defatted Tenebrio molitor Larva Fermentation Extract Modifies Steatosis, Inflammation and Intestinal Microflora in Chronic Alcohol-Fed Rats. Nutrients 2020, 12, 1426. [CrossRef]

9. Rehm, J.; Mathers, C.; Popova, S.; Thavorncharoensap, M.; Teerawattananon, Y.; Patra, J. Global Burden of Disease and Injury and Economic Cost Attributable to Alcohol Use and Alcohol-Use Disorders. Lancet 2009, 373, 2223-2233. [CrossRef]

10. Seitz, H.K.; Bataller, R.; Cortez-Pinto, H.; Gao, B.; Gual, A.; Lackner, C.; Mathurin, P.; Mueller, S.; Szabo, G.; Tsukamoto, H. Alcoholic Liver Disease. Nat. Rev. Dis. Primers 2018, 4, 1-22. [CrossRef]

11. Tajiri, K.; Shimizu, Y. Branched-Chain Amino Acids in Liver Diseases. World J. Gastroenterol. 2013, 19, 7620-7629. [CrossRef] [PubMed]

12. Tedesco, L.; Corsetti, G.; Ruocco, C.; Ragni, M.; Rossi, F.; Carruba, M.O.; Valerio, A.; Nisoli, E. A Specific Amino Acid Formula Prevents Alcoholic Liver Disease in Rodents. Am. J. Physiol. Gastrointest. Liver Physiol. 2018, 314, G566-G582. [CrossRef] [PubMed]

13. Lee, D.Y.; Kim, E.H. Therapeutic Effects of Amino Acids in Liver Diseases: Current Studies and Future Perspectives. J. Cancer Prev. 2019, 24, 72-78. [CrossRef] [PubMed]

14. Mavrelis, P.G.; Ammon, H.V.; Gleysteen, J.J.; Komorowski, R.A.; Charaf, U.K. Hepatic Free Fatty Acids in Alcoholic Liver Disease and Morbid Obesity. Hepatology 1983, 3, 226-231. [CrossRef] 
15. Clish, C.B. Metabolomics: An Emerging but Powerful Tool for Precision Medicine. Cold Spring Harb. Mol. Case Stud. 2015, 1, a000588. [CrossRef]

16. Ma, T.; Li, Y.; Zhu, Y.; Jiang, S.; Cheng, C.; Peng, Z.; Xu, L. Differential Metabolic Pathways and Metabolites in a C57BL/6J Mouse Model of Alcoholic Liver Disease. Med. Sci. Monit. 2020, 26, e924602. [CrossRef]

17. Dong, Y.; Qiu, P.; Zhao, L.; Zhang, P.; Huang, X.; Li, C.; Chai, K.; Shou, D. Metabolomics Study of the Hepatoprotective Effect of Phellinus igniarius in Chronic Ethanol-Induced Liver Injury Mice using UPLC-Q/TOF-MS Combined with Ingenuity Pathway Analysis. Phytomedicine 2018, 74, 152697. [CrossRef]

18. Harada, S.; Takebayashi, T.; Kurihara, A.; Akiyama, M.; Suzuki, A.; Hatakeyama, Y.; Sugiyama, D.; Kuwabara, K.; Takeuchi, A.; Okamura, T.; et al. Metabolomic Profiling Reveals Novel Biomarkers of Alcohol Intake and Alcohol-Induced Liver Injury in Community-Dwelling Men. Phytomedicine 2020, 74, 152697.

19. Lian, J.S.; Liu, W.; Hao, S.R.; Guo, Y.Z.; Huang, H.J.; Chen, D.Y.; Xie, Q.; Pan, X.P.; Xu, W.; Yuan, W.X.; et al. A Serum Metabonomics Study on the Difference Between Alcohol-and HBV-Induced Liver Cirrhosis by Ultraperformance Liquid Chromatography Coupled to Mass Spectrometry Plus Quadrupole Time-of-Flight Mass Spectrometry. Chin. Med. J. 2011, 124, 1367-1373.

20. Lee, H.S.; Seo, C.; Kim, Y.A.; Park, M.; Choi, B.; Ji, M.; Lee, S.; Paik, M.J. Metabolomic Study of Polyamines in Rat Urine following Intraperitoneal Injection of $\gamma$-Hydroxybutyric Acid. Metabolomics 2019, 15, 58. [CrossRef]

21. Seo, C.; Hwang, Y.H.; Kim, Y.; Joo, B.S.; Yee, S.T.; Kim, C.M.; Paik, M.J. Metabolomic Study of Aging in Mouse Plasma by Gas Chromatography-Mass Spectrometry. J. Chromatogr. B Analyt. Technol. Biomed. Life Sci. 2016, 1025, 1-6. [CrossRef]

22. Worley, B.; Powers, R. Multivariate Analysis in Metabolomics. Curr. Metabolomics 2013, 1, 92-107. [PubMed]

23. Maezono, K.; Mawatari, K.; Kajiwara, K.; Shinkai, A.; Maki, T. Effect of Alanine on D-Galactosamine-Induced Acute Liver Failure in Rats. Hepatology 1996, 24, 1211-1216.

24. Freudenberg, A.; Petzke, K.J.; Klaus, S. Dietary L-Leucine and L-Alanine Supplementation Have Similar Acute Effects in the Prevention of High-Fat Diet-Induced Obesity. Amino Acids 2013, 44, 519-528. [CrossRef] [PubMed]

25. Zeb, A.; Rahman, S.U. Protective Effects of Dietary Glycine and Glutamic Acid toward the Toxic Effects of Oxidized Mustard Oil in Rabbits. Food Funct. 2017, 8, 429-436. [CrossRef] [PubMed]

26. Park, J.G.; Tak, W.Y.; Park, S.Y.; Kweon, Y.O.; Jang, S.Y.; Lee, Y.R.; Bae, S.H.; Jang, J.Y.; Kim, D.Y.; Lee, J.S.; et al. Effects of Branched-Chain Amino Acids (BCAAs) on the Progression of Advanced Liver Disease: A Korean Nationwide, Multicenter, Retrospective, Observational, Cohort study. Medicine 2017, 96, e6580. [CrossRef]

27. Puchalska, P.; Crawford, P.A. Multi-Dimensional Roles of Ketone Bodies in Fuel Metabolism, Signaling, and Therapeutics. Cell Metab. 2017, 25, 262-284. [CrossRef]

28. Chen, Y.; Ouyang, X.; Hoque, R.; Garcia-Martinez, I.; Yousaf, M.N.; Tonack, S.; Offermanns, S.; Dubuquoy, L.; Louvet, A.; Mathurin, P.; et al. $\beta$-Hydroxybutyrate Protects from Alcohol-Induced Liver Injury via a Hcar2-cAMP Dependent Pathway. J. Hepatol. 2018, 69, 687-696. [CrossRef]

29. Ajmo, J.M.; Liang, X.; Rogers, C.Q.; Pennock, B.; You, M. Resveratrol Alleviates Alcoholic Fatty Liver in Mice. Am. J. Physiol. Gastrointest. Liver Physiol. 2008, 295, G833-G842. [CrossRef]

30. Li, Q.; Xie, G.; Zhang, W.; Zhong, W.; Sun, X.; Tan, X.; Sun, X.; Jia, W.; Zhou, Z. Dietary Nicotinic Acid Supplementation Ameliorates Chronic Alcohol-Induced Fatty Liver in Rats. Alcohol. Clin. Exp. Res. 2014, 38, 1982-1992. [CrossRef]

31. Rodríguez-Gallego, E.; Guirro, M.; Riera-Borrull, M.; Hernandez-Aguilera, A.; Marine-Casado, R.; Fernandez-Arroyo, S.; Beltran-Debon, R.; Sabench, F.; Hernandez, M.; del Castillo, D. Mapping of the Circulating Metabolome Reveals $\alpha$-Ketoglutarate as a Predictor of Morbid Obesity-Associated Non-Alcoholic Fatty Liver Disease. Int. J. Obes. 2015, 39, 279-287. [CrossRef] [PubMed]

32. Spector, S.R.; Mayan, H.; Loebstein, R.; Markovits, N.; Priel, E.; Massalha, E.; Shafir, Y.; Gueta, I. Pyroglutamic Acidosis as a Cause for High Anion Gap Metabolic Acidosis: A Prospective Study. Sci. Rep. 2019, 9, 3554. [CrossRef] [PubMed]

33. Inoue, S.; Okita, Y.; de Toledo, A.; Miyazaki, H.; Hirano, E.; Morinaga, T. Pyroglutamic Acid Stimulates DNA Synthesis in Rat Primary Hepatocytes through the Mitogen-Activated Protein Kinase Pathway. Biosci. Biotechnol. Biochem. 2015, 79, 795-798. [CrossRef] [PubMed]

34. Guelakis, M.P.; Lee, J.; Rosa, J.G.; Madison, S.A.; Damodaran, A.; Kumari, A.; Huang, N.; Harichian, B. Personal Care Compositions with Glutathione Precursor Comprising 4-Substituted Resorcinols and Amino Acids. USA Patent PCT/CN2017/116999, 28 June 2018. 
35. Di Miceli, M.; Gronier, B. Pharmacology, Systematic Review and Recent Clinical Trials of Metadoxine. Rev. Recent Clin. Trials 2018, 13, 114-125. [CrossRef]

36. Lim, J.; Li, L.; Jacobs, M.D.; Kistler, J.; Donaldson, P.J. Mapping of Glutathione and Its Precursor Amino Acids Reveals a Role for GLYT2 in Glycine Uptake in the Lens Core. Investig. Ophthalmol. Vis. Sci. 2007, 48, 5142-5151. [CrossRef] [PubMed]

37. Mayatepek, E. Current Opinion in Pediatric Metabolic Disease. J. Pediat. Sci. 2011, 3, e64.

38. Bando, K.; Kunimatsu, T.; Sakai, J.; Kimura, J.; Funabashi, H.; Seki, T.; Bamba, T.; Fukusaki, E. GC-MS-Based Metabolomics Reveals Mechanism of Action for Hydrazine Induced Hepatotoxicity in Rats. J. Appl. Toxicol. 2011, 31, 524-535. [CrossRef]

39. Wu, H.; Feng, F. Untargeted Metabolomic Analysis using LC-TOF/MS and LC-MS/MS for Revealing Metabolic Alterations Linked to Alcohol-Induced Hepatic Steatosis in Rat Serum and Plasma. RSC Adv. 2016, 6, 28279-28288. [CrossRef]

40. Wang, M.; Zhang, X.; Ma, L.J.; Feng, R.B.; Yan, C.; Su, H.; He, C.; Kang, J.X.; Liu, B.; Wan, J. Omega-3 Polyunsaturated Fatty Acids Ameliorate Ethanol-Induced Adipose Hyperlipolysis: A Mechanism for Hepatoprotective Effect against Alcoholic Liver Disease. Biochim. Biophys. Acta Mol. Basis Dis. 2017, 1863, 3190-3201. [CrossRef]

41. Piquet, M.A.; Roulet, M.; Nogueira, V.; Filippi, C.; Sibille, B.; Hourmand-Ollivier, I.; Pilet, M.; Rouleau, V.; Leverve, X.M. Polyunsaturated Fatty Acid Deficiency Reverses Effects of Alcohol on Mitochondrial Energy Metabolism. J. Hepatol. 2004, 41, 721-729. [CrossRef]

42. Huang, L.L.; Wan, J.B.; Wang, B.; He, C.W.; Ma, H.; Li, T.W.; Kang, J.X. Suppression of Acute Ethanol-Induced Hepatic Steatosis by Docosahexaenoic Acid is Associated with Downregulation of Stearoyl-CoA Desaturase 1 and Inflammatory Cytokines. Prostaglandins Leukot. Essent. Fatty Acids 2013, 88, 347-353. [CrossRef] [PubMed]

43. Saini, R.K.; Keum, Y.S. Omega-3 and Omega-6 Polyunsaturated Fatty Acids: Dietary Sources, Metabolism, and Significance-A Review. Life Sci. 2018, 203, 255-267. [CrossRef] [PubMed]

44. Xiong, F.; Guan, Y.S. Cautiously using Natural Medicine to Treat Liver Problems. World J. Gastroenterol. 2017, 23, 3388-3395. [CrossRef] [PubMed]

45. Kim, J.W.; Lee, G.; Moon, S.M.; Park, M.J.; Hong, S.K.; Ahn, Y.H.; Kim, K.R.; Paik, M.J. Metabolomic Screening and Star Pattern Recognition by Urinary Amino Acid Profile Analysis from Bladder Cancer Patients. Metabolomics 2010, 6, 202-206. [CrossRef]

46. Seo, C.; Park, M.; Choi, B.; Lee, S.; Paik, M.J. Metabolomic Analysis of Urinary Organic Acids following Intraperitoneal Injection with $\gamma$-Hydroxybutyric Acid in Rats. Metabolomics 2016, 12, 190. [CrossRef]

47. Seo, C.; Yoon, J.; Rhee, Y.; Kim, J.J.; Nam, S.J.; Lee, W.; Lee, G.; Yee, S.T.; Paik, M.J. Simultaneous Analysis of Seven 2-Hydroxy Fatty Acids as Tert-Butyldimethylsilyl Derivatives in Plasma by Gas Chromatography-Mass Spectrometry. Biomed. Chromatogr. 2015, 29, 156-160. [CrossRef]

Publisher's Note: MDPI stays neutral with regard to jurisdictional claims in published maps and institutional affiliations.

(C) 2020 by the authors. Licensee MDPI, Basel, Switzerland. This article is an open access article distributed under the terms and conditions of the Creative Commons Attribution (CC BY) license (http://creativecommons.org/licenses/by/4.0/). 